\title{
Witnessing adults' violence: the effects on children and adolescents
}

\author{
Dora Black
}

Children, like adults, can directly experience or be witness to interpersonal violence either within or outside the family, on one or repeated occasions. Intra-familial violence may result in the death or serious disablement of a parent or child, or may be experienced as child sexual abuse or chronic domestic violence. Non-familial violence includes urban violence now endemic in some communities, war and civil conflict, and vicarious violence such as in films and on television. Traumatic events can also occur by natural forces, for example, earthquakes, volcanic eruptions, hurricanes. This review will focus mainly on the effects on children of witnessing severe or repeated violence, sometimes resulting in death, occurring to a member of their family, perpetrated either by a parent, step-parent or cohabitee or by a person or persons unrelated to them, although it will draw on studies of other traumatic experiences where relevant.

The psychological symptoms of witnessing violence are not the only consequences, particularly of violence resulting in bereavement. The effects of the disruption of attachment bonds, particularly in young children who are totally dependent on their carers, as well as the consequences of subsequent placements and possibly frequent changes of carers need consideration, as do issues such as contact with a perpetrator parent. Preventive interventions and therapies will be reviewed and some forensic issues, both civil and criminal, will be considered as they affect mental health professionals. The subject of child sexual abuse is well-covered elsewhere (Smith \& Bentovim, 1994) as are the effects of physical abuse on the child victim (Skuse \& Bentovim, 1994). Television violence and its effects on children has been reviewed by Black \& Newman (1995).

\section{Case vignettes}

Jill

Jill, aged four years, was living with foster-parents following the death of her baby sister, who was admitted to hospital with multiple injuries two weeks earlier. Her parents were held in custody and charged with manslaughter. She was referred by her social worker for help with breaking the news of the death and understanding the cause of her parents' disappearance. She was mute at first, but through play using dolls she was able to demonstrate that she had witnessed her parents beating her baby sister and showed how the baby had been thrown against a wall by her father. Jill was found to be suffering from post-traumatic stress disorder (PTSD), with nightmares relating to the beatings she had witnessed, flashbacks, repetitive aggressive play and difficulty in concentrating. She had reverted to wetting the bed and would not eat lumpy food. She was afraid of the dark and had difficulty in getting to sleep. She reacted with disbelief to the news that her sister was dead. She needed help to understand the concept of death (which does not usually develop fully until at least five years of age), and among other therapeutic measures, she was taken to see her sister's body to aid in this understanding.

In addition to PTSD, she was suffering from the abrupt separation from her only attachment figures at an age when attachment is at its height. She was ambivalently attached to her parents because of their treatment of her sister, but her feelings were complex - she demonstrated

Dora Black has recently retired from her post as Director and Consultant Child and Adolescent Psychiatrist at the Traumatic Stress Clinic, 73 Charlotte Street, London W1P 1LB which she co-founded. She is Honorary Consultant at the Royal Free Hospital, Great Ormond Street Hospital and the Tavistock Clinic and is Honorary Senior Lecturer to University College, London. 
triumph at being the preferred child (she had never been ill-treated physically), together with fear that her resentment of the new baby's arrival had 'caused' the parental ill-treatment. These themes emerged in the regular sessions with a clinical child psychologist which involved cognitivebehavioural therapy to treat the PTSD, combined with analytic child psychotherapy to deal with the problems posed by the separation and guilt. At the same time her foster-carers needed guidance about her management, and her parents and social worker needed advice about making the contact visits with the parents in their separate prisons as therapeutic as possible. A psychiatric report was also required for care proceedings in the family proceedings court and a report for the Criminal Injury Compensation Authority enabled compensation to be awarded in due course for her PTSD and traumatic bereavement.

\section{Matthew}

Matthew was 15 years old when he and his older brother were disturbed at breakfast by the sound of screaming coming from their parents' bedroom. Their parents had recently separated and their mother had moved out of the family home, but returned daily to make their meals and do the housework. She had gone upstairs to fetch some clothes. Their father had followed her. They ran upstairs to find the bedroom locked. They found a spare key, and entered to find their mother expiring in a pool of blood, her throat cut, and their father also seriously injured from selfinflicted wounds. They called the emergency services, and comforted their mother as she died, kneeling in the copious quantities of blood which covered the walls as well as the floor. They were subsequently placed in foster-care, there being no relatives to care for them.

Matthew was referred by his general practitioner (GP) three weeks later because of severe problems with sleep, including nightmares and alcohol misuse leading to uncontrollable aggression. He subsequently became delinquent, was unable to settle with a series of foster-carers, was frequently drunk, failed at school (he had been about to sit his GCSE exams a few months after the death of his mother) and experienced murderous feelings towards his father, who had survived the suicide attempt and was in a secure psychiatric unit. Matthew became psychotic on the first anniversary of his mother's death, with auditory hallucinations and feelings of persecution, and spent some time as an in-patient in a psychiatric adolescent unit.
Lily

Lily, aged seven years, was the oldest of three children. Her mother was only 16 years old when she was born, and her father, 19. He was unemployed and spent his days with his friends drinking and gambling. The family were chronically short of money and this led to rows between the parents. The father often physically assaulted the mother when he came home drunk and she chastised him. Lily would sometimes get hurt when she tried to intervene to protect her mother. The children were on the Child Protection Register and the local authority had, over the years, poured a lot of resources into the situation, but little had changed.

One night Lily's mother was beaten unconscious and had to be admitted to hospital. Lily's father was arrested and charged with grievous bodily harm. The children were received into care, placed with foster-carers and were referred for psychiatric assessment. Lily and her siblings were found to be underweight, although physically healthy and uninjured. Lily behaved as a parental child, competing with the foster-carers for the disciplining and nurture of her siblings. She was of average ability but poor attainment, and had a poor attendance record at school. She told of her lack of sleep due to her vigilance at home and the fostercarers described her night terrors. She jumped at the slightest noise and did not know how to play with the toys provided at the assessment interview. Lily was diagnosed as suffering from PTSD. She responded to cognitive-behavioural therapy for this, and to good nurture. An assessment of her parents indicated that they were suitable for and amenable to therapeutic work to improve their parenting abilities and the family were admitted to a residential family treatment unit after the father was released from prison and the mother from hospital.

\section{Amir}

Amir was nine years old when guerrillas attacked his village in an African country where there was a long-term civil war. He hid from them but found on emerging that his whole village had been slaughtered, including his parents and siblings. After wandering in the woods, he was found by members of a charitable organisation who ran a refugee camp. He was fed and clothed, but as he was physically unscathed he received no medical attention in spite of crippling nightmares and other symptoms of PTSD. Eventually, after four years, he came to the UK to live with an aunt who was also a refugee. The school to which he was sent referred him to a child psychiatric service as he was 
unteachable and unmanageable. He was found a place in a small educational unit, and patient and prolonged psychotherapy eventually enabled him to unburden himself of his experiences, to grieve for his family and begin to trust the adult world. His aunt also needed help with her grief, as well as support during her nephew's temporary increased disturbance as he recalled the horrors he had experienced.

\section{Witnessing violence}

The above case histories illustrate many of the phenomena associated with witnessing severe violence. Children and adults who witness horrific events, especially if they know the victims, are at greatly enhanced risk of developing psychiatric disorders, of which the most frequent is PTSD(DSMIV; American Psychiatric Association, 1994). They are also at higher risk for developing pathological grief reactions after bereavement, including anxiety and depressive disorders (Black \& Young, 1995). In children, severe symptomatology may interfere with normal development, their ability to learn and make academic progress, their capacity for social relationships and may distort family functioning. In very young children, sudden and repeated disruptions of attachment bonds may lead to attachment disorders.

Psychological trauma has been defined as: "the experience of an inescapable stressful event that overwhelms one's existing coping mechanisms" (Van der Kolk \& Fisler, 1995). Coping mechanisms are fewer in children than in adults, as they are likely to have had much less experience of having to cope with or escape from stressful situations. They are therefore more vulnerable to develop symptoms. In order to understand some of the phenomena of PTSD it is helpful to refer to the way in which perceptions are processed by the brain and how the stage of development and emotional state influence this processing.

\section{Processing traumatic perceptions}

Traumatic experiences become encoded by the brain differently from non-traumatic events. Only part of the experience can be processed and the overriding need to diminish emotional flooding may lead to the focusing of attention away from the trauma. Excessive stress may also directly impair hippocampal functioning which mediates the focal attention needed for explicit (or declarative) memory functioning. Thus many of the traumatic events may be processed without focal attention and be encoded in implicit memory (information expressed through performance rather than recollection), not easily consciously retrieved and not under conscious control. Such learning may be state-dependent and lead to dissociative experiences, with certain traumatic memories being accessible only when the individual is in a similar highly-aroused emotional state to that experienced when the trauma occurred, or only retrievable by one sensory modality.

In order to process information into the long-term memory store, a person needs to attach associations to it. Young children's information processing is very reliant, certainly before the age of 3-5 years, on reinforcement and association provision by their parents and other adults. They are also more likely to be flooded by their emotions - fear, helplessness and terror in the face of trauma. If, as has been suggested, the phenomenology of PTSD can be understood, at least in part, as due to impaired processing of cognitive data, related to overwhelming emotional arousal, then it is likely that children, even more than adults, will be vulnerable to developing PTSD. Early traumatic experiences can even alter the manner and rate of maturation of different brain structures, permanently altering their relative influence in appraising and responding to danger (Perry et al, 1995).

For a full discussion of memory and of various theories of PTSD see Lee \& Turner (1997), Van Velsen (1997), McIvor (1997) and Siegel (1997). For an interesting and important exposition on the early organisation of memory in older children and adolescents see Pynooset al (1997).

\section{Intra-familial violence}

\section{Homicide of a parent}

In the largest published study of child survivors of uxoricide (spouse-killing; Harris-Hendriks et al, 1993) it was found that approximately half the children had witnessed the killing of one parent by the other. Most of the children who had either seen the actual killing, heard it or come in on the dead body of a parent immediately afterwards, developed PTSD ( 26 out of 33 witnesses). Most of those who did not witness the killing did not develop PTSD, although a substantial minority did (18 out of 56 non-witnesses). Most of these children had been witnesses of chronic and escalating domestic violence preceding the actual homicide. This study 
was carried out before criteria of PTSD more suitable for young children had been developed (Scheeringa et al, 1995). Most of the children in the study were under 11 years of age and $40 \%$ were under five years old at the time of the killing. Had the alternative criteria for PTSD been applied, the correlations might have been even more impressive.

In a postal questionnaire follow-up study of these children (conducted by D.B. and colleagues; futher details available from the author upon request) attachment problems were a prominent feature, particularly in the younger children, in those who had had more changes of placement and in those living with the perpetrator's family. This finding accords with clinical observation about the effect on children of disrupted attachments and has profound implications for personality development and the formation and maintenance of intimate relationships with future partners and offspring. The incidence of behavioural and emotional problems was also considerably higher than in a population comparison group, although those children who had witnessed the killing were more likely to have received treatment than those who did not witness it, and this may have resulted in relatively better outcomes than would have been present in a completely untreated group.

A large-scale telephone survey of 12500 adults in the USA found that $9.3 \%$ had lost a family member or friend through a homicide. At some time in their lives $23.3 \%$ developed PTSD and nearly 5\% had PTSD in the preceding six months. Survivors who had experienced the homicide during their childhood were equally likely to have developed PTSD as those who were adults. Amick-McMullan et al (1991) note that their findings imply that 16.4 million Americans had become the indirect victims of homicide and five million had lost immediate family members. Only $6 \%$ of the survivors witnessed the killing, yet $19 \%$ developed homiciderelated PTSD, indicating that witnessing is not the only route to developing PTSD. Unfortunately, we are not told what proportion of those who witnessed the killing developed PTSD; being a retrospective study, it probably underestimates the proportion of those developing symptoms (Amick-McMullan et al, 1991).

\section{Siblings}

The effects on children of witnessing or otherwise experiencing the homicide of a sibling, or of a sibling being attacked and seriously hurt, have received little attention. This is surprising given that sibling relationships are normally among the longest lasting. In 1994, in England and
Wales, 56 children and adolescents under 16 years old, per million of the population, were the direct victims of homicide (which includes murder, manslaughter and infanticide). Children under one year of age are at four times greater risk of becoming victims of homicide than are older children or adults (Home Office, 1994). Children are most likely to be killed by persons known to them, a parent being the most likely perpetrator. Siblings suffer indirectly from these crimes and may also be victims of related violence and abuse. The resulting change in family circumstances may bring about further traumatisation for the young person(s) involved.

A comparative study of 10 siblings who had lost a brother or sister by accidental death with 10 who had lost a brother or sister by homicide found that all the siblings reported symptoms of PTSD, with 45\% meeting criteria for PTSD. Parents, however, were not necessarily aware of their child's distress, perhaps because they were trying to cope with their own distress (35\% had PTSD; significantly more of the parents of the murdered children than of the accidental deaths). The siblings in the accident and murder groups did not differ significantly in PTSD severity. Higher levels of parental PTSD were also associated with higher levels of PTSD in the surviving sibling (Applebaum \& Burns, 1991). Although this study is of limited value because of small groups, self-selection and a wide age range, it is almost the only available study of children who were traumatically bereaved of a sibling .

Clinical experience indicates that the non-injured sibling of a child who is injured (for example, a child surviving a road-traffic accident or a disaster) may experience relative neglect within the family as parental attention and energy is concentrated on the more demanding and overtly suffering child. This can engender feelings of jealousy, then guilt for those feelings, which can lead to distortions of family relationships.

\section{Domestic violence}

Until recently, an under-researched, and indeed under-recognised, source of child psychiatric disorder and later poor parental functioning, is the experience of witnessing repeated domestic violence, and feeling highly emotionally aroused and helpless to prevent it. Physical assault on a spouse is the second most frequent type of crime reported to the police and constitutes $25 \%$ of all reported violent crime. The largest single category of assaults is domestic violence, $80 \%$ of which is against women (Home Office, 1993). Children who witness repeated or extreme domestic 
violence, including rape, have a higher incidence of PTSD (Pynoos \& Nader, 1988; Masten et al, 1990) and of conduct disorder (Emery, 1982) than those who do not. Studies of children in women's refuges (Jaffe et al, 1990) show particularly high levels of anxiety and PTSD, but these children experience many other adversities including disruption of home and school. Physical and sexual abuse of the child is significantly associated with domestic violence and will inflate the incidence of serious psychiatric problems in children who witness domestic violence (Straus et al, 1980).

A small study in Australia which attempted to eliminate confounding stressors, compared 20 children living in homes with domestic violence with a matched non-violent control group, excluding other possible causes of PTSD (physical and sexual abuse, experience of serious accidents and disasters). Nearly all of the children in households with domestic violence had PTSD of moderate or severe degree while none of the control group had PTSD. The group who had experienced domestic violence also showed high anxiety levels (K. Kilpatrick, personal communication, 1998).

As children grow older, initial sympathy for a battered mother may be replaced by anger and overt hostility towards her. Conduct disorders, particularly among boys, are more common as an adolescent response to ongoing domestic violence, including running away from home. The evidence is that children who witness repeated assaults on their mother by their father or step-father carry a high burden of psychological pathology (Black \& Newman, 1996).

\section{Community violence}

In the UK most of the assaults and killings children may witness will occur between family members. This is different in some other countries and in some neighbourhoods; for example Northern Ireland, USA and some African countries. The number of children in the UK known to have been killed by strangers has averaged about six or seven per year over the past 20 years, and the statistics have shown no increasing trend. In the USA, where the possession of guns is common and where chronic community violence has been characterised as a public health epidemic and equivalent to growing up in a war zone, one in 10 children under six years of age and three-quarters of high school children in some communities will have witnessed a serious assault or homicide. There is a significant association between domestic and community violence, and living with parents who may be numbed, frightened or depressed will make it difficult for the children to feel secure. Children's reactions to violence depend on the level of exposure, their stage of development and the availability of family and community supports, but for young children it may lead to disorders of attachment, and for older ones the likelihood of PTSD and conduct disorders (Osofsky, 1995)

\section{War and civil conflict}

In the West we have not had to experience the impact of a disaster on the same scale as places like Rwanda, where UNICEF estimates that there are 95000 orphans (UNICEF, 1995) or Skopje, where four refugee camps were, in 1992, 'home' to over 7000 refugee children from Bosnia (Parry Joneset al, 1995). In Rwanda, half the orphans had been threatened with death themselves, a quarter had been injured, a fifth had witnessed rapes and nearly two-thirds had witnessed massacres. Children in situations of war and conflict may be mal- or under-nourished, physically at risk, injured or mutilated. If the infrastructure has collapsed they may not receive education or adequate medical care. They are likely to be inadequately treated for chronic pre-existing conditions such as asthma, diabetes or congenital disorders (cystic fibrosis, for example), may have inadequate housing, especially if they are refugees, and may suffer from the consequences of poverty and displacement. Their parents may be absent, chronically depressed, fearful, injured or physically ill, so that their parenting may be affected. All these factors increase the risk of the child developing a psychiatric disorder.

Children caught up in traumatic events are likely to be separated from familiar care-takers, either through their death, capture or serious injury, or because of evacuation, displacement or maladministration. The effects of this are still uncertain (Najarianet al, 1996). Reactive attachment disorders (World Health Organization, 1992) or degrees of separation anxiety may result in clinging behaviour, crying on separation, hostility to the parent or carer, or sleeping, toileting and eating disturbances, especially in younger children. Children separated from their parents in situations of war are more vulnerable to physical and sexual abuse, leading to further traumatisation and resulting in disorders of personality (Ressler et al, 1988). Useful reviews of the effects on children of being caught up in war situations are provided by Richman (1993a) and Jensen \& Shaw (1993). 


\section{Interventions and therapies}

Children and adolescents caught up in violent episodes and who become dysfunctional need a full evaluation and assessment. Understanding the way in which traumatic memories are processed helps clinicians to understand the phenomena of PTSD, especially nightmares and flashbacks, and opens the way to a rational approach to helping the victims of trauma. It may be possible, if intervention is early enough, to inoculate against the development of PTSD by helping the individual to process the images and to attach associations. Early claims that critical incident stress debriefing could prevent PTSD (Robinson \& Mitchell, 1993; Mitchell, 1983) have been questioned (Raphael \& Meldrum, 1995; Bisson et al, 1997) and it is likely that, for children at least, a brief one- or two-session preventive intervention is not sufficient. Nevertheless, if communities plan their responses and train a group of workers before a disaster occurs, such action is likely to reduce suffering (Allen, 1991; Yule \& Gold, 1993). Once fullblown symptoms of PTSD set in, other techniques need to be used, sometimes in combination, including cognitive-behavioural therapy (Kendall, 1991), psychotherapy (Emanuel \& Mendelsohn, 1997), eye-movement desensitisation (Shapiro, 1995) and medication (Newman, 1997).

One of the few studies of the treatment of PTSD in children found positive results from a brief intervention after the Armenian earthquake (Goenjian et al, 1997).

Where there has been a bereavement, children may benefit from bereavement counselling in order to help them to understand death and mourn their dead parent or sibling (Young \& Black, 1997). Children who have been traumatically bereaved need to have the trauma dealt with in therapy before they are able to benefit from grief work (Pynoos, 1992).

Marans \& Cohen (1993) have suggested strategies for intervention with children where there is urban violence, which include training police to recognise and work with traumatised children. Warner \& Weist (1996) review treatment methods for urban youth witnesses of violence.

In developing countries there are few psychiatrists and even fewer child psychiatrists or psychologists. Tackling the enormous task of reducing the existing suffering and distress involves the 'cascade' method of treatment in which a few highly trained and experienced professionals, often from abroad, train local professionals, who in turn train volunteers and lay workers. One such project based in Mostar, Bosnia, involved British clinical psychologists training and supervising teachers and health professionals to support and help traumatised children. A similar model was used by Richman to train teachers to work with children caught up in Mozambique's civil war (Richman, 1993b).

\section{Forensic issues}

\section{Civil child forensic psychiatry}

The Children Act 1989 came fully into operation in 1991. It brought together and unified legislation pertaining to children which had previously been scattered throughout many other Acts. It brought into use the concept of 'significant harm' as the sole criterion for the making of a care order or a supervision order to the local authority. Harm in this context included emotional harm, and assessing this and giving expert evidence in the family proceedings court is now an important part of the work of many child psychiatrists and psychologists (Blacket al, 1991). Assessing children who have witnessed violence must involve not only evaluation for the presence of psychiatric or psychological disorders, but also their attachment needs, where they should live if it is not possible or desirable to live with parent(s), and what contact they should have with a perpetrator parent. They may also be entitled to criminal injury or other compensation. Clearly the children's parents and/or care-takers must be part of the assessment, which has to include an evaluation of the effect of any traumatic incident on their parenting functions (Harris-Hendriks et al, 1993). Domestic violence may continue after parents separate and a major difficulty may arise if an order for contact is made to a violent father, which the mother refuses to carry out because of fear engendered by having to have contact with her violent ex-partner. The court may commit her to prison for contempt of court. A recent review of contact arrangements in cases of domestic violence in two countries contrasts the situation in Denmark, where there is a presumption of no contact where there was domestic violence until or unless it can be arranged safely for mother and child, with that in England, where contact is considered the right of the child and to be in their best interests, even where there has been domestic violence (Hester \& Radford, 1996). New Zealand has enacted legislation similar to Denmark's and, interestingly, in Scotland the presumption is no contact until the parent establishes a case for it benefiting the child (Hall, 1997). 


\section{Criminal forensic psychiatry}

If a person's spouse or child is killed or seriously assaulted, the perpetrator is likely to receive a prison sentence. Assessment of whether the child will benefit from contact with an incarcerated parent must include an interview with the parent to assess mental state, capacity for remorse and apology, as well as an evaluation of the impact on the present carers of any contact order. One cannot rely on adult forensic psychiatrists' evaluations as they must have the well-being of their patient (the parent) as a prime consideration and may only consider risk to the public when deciding whether a prisoner can be released and can receive child visitors, not the impact on the child who may have witnessed the killing of his mother (Harris-Hendrikset al, 1993). A significant minority of domestic killers have mental health problems or problems related to substance misuse. Domestic violence often occurs under the influence of alcohol and violence may continue after separation. Injunctions without power of arrest are often flouted and may not protect the child or mother, although the recent Protection from Harrassment Act 1997 may have more success.

\section{Conclusion}

Children are the innocent victims of adult violence, man-made and natural disasters, and appear to be at the same or higher risk of PTSD and other psychiatric disorders compared with adults. More research is needed to determine the effects of age, development, family and community factors, and longitudinal follow-up studies will help to assess whether early intervention has adverse or beneficial long-term consequences. Care needs to be taken in interpreting studies from different populations and conflicts, and conclusions drawn from observations made on clinical populations cannot be transferred to non-clinical ones. Protective factors appear to include being shielded from witnessing horrific sights and sounds, not being separated from familiar care-takers, resilience and courage in their parents and an open communication between the adults and children. Children who have experienced horrific events appear to benefit from an opportunity to communicate about their experiences and help in understanding them, access to psychiatric services, advocacy, legal protection, and clear long-term plans about where they should live and go to school, whom they should have access to and
Box 1. Points to remember

Children are at least as vulnerable as adults to developing post-traumatic symptoms

Witnessing violence is associated with a high incidence of PTSD

Other conditions associated with witnessing violence include attachment disorders, emotional and conduct disorders and academic failure

Early intervention may prevent or limit psychological distress, and can give an opportunity to influence placement of the child and assess treatment and other needs

Specific therapies to treat PTSD exist but need further evaluation with children

Witnessing traumatic events may have a lasting effect on mental health, educational progress and personality development

what treatment, if any, they need. Early intervention post-trauma may prevent or limit psychological distress, and attention to the provision of substitute parenting where necessary, medical care and education, housing and nutrition are essential to minimising the secondary effects of traumatic events. Adults may not be prepared to bring children for rapid help because they fear that the children may be disturbed by such ventilation, while the children fear upsetting their care-takers and collude in avoiding the subject. They may be entitled to compensation for psychological injuries.

Witnessing traumatic events may have a lasting effect on the ability of children to develop and learn and can affect their mental health, perhaps permanently (see Box 1).

\section{References}

Allen, T. (1991) Disasters: Planning for a Caring Response. London: HMSO.

Amick-McMullan, A., Kilpatrick, D. G. \& Resnick, H. S. (1991) Homicide as a risk factor for PTSD among surviving family members. Behaviour Modification, 15, 545-559.

American Psychiatric Association (1994) Diagnostic and Statistical Manual of Mental Disorders (4th edn) (DSM-IV). Washington, DC:APA.

Applebaum, D. R. \& Burns, G. L. (1991) Unexpected childhood death - post-traumatic stress disorder in surviving siblings and parents. Journal of Clinical Child Psychology, 20, 114-120. 
Bisson, J. I., Jenkins, P. L., Alexander, J., et al (1997) Randomised controlled trial of psychological debriefing for victims of acute burn trauma. British Journal of Psychiatry, 171, 78-81.

Black, D., Wolkind, S. \& Harris-Hendriks, J. (1991) Child Psychiatry and the Law (2nd edn). London: Gaskell.

— \& Newman, M. (1995) Television violence and children. British Medical Journal, 310, 273-274.

- \& - (1996) Children and domestic violence: a review. Clinical Child Psychology and Psychiatry, 1, 79-88.

Black, D. \& Young, B. (1995) Bereaved children: risk and preventive intervention. In Handbook of Studies in Preventive Psychiatry (eds B. Raphael \& G. D. Burrows), pp. 225-244. Oxford: Elsevier.

Emanuel, R. \& Mendelsohn, A. (1997) Psychodynamic psychotherapy. In Psychological Trauma: A Developmental Approach (eds D. Black, J. Harris-Hendriks, M. Newman, et al), pp. 287-293. London: Gaskell.

Emery, R. E. (1982) Interparental conflict and the children of discord and divorce. Psychological Bulletin, 92, 310-330.

Goenjian, A., Pynoos, R. S. \& Karayan, I. (1997) Outcome of psychotherapy among pre-adolescents after the 1988 earthquake in Armenia. American Journal of Psychiatry, 154, 536-542.

Hall, V. (1997) Domestic violence and contact. Family Law 27, 813-818.

Harris-Hendriks, J., Black, D. \& Kaplan, T. (1993) When Father Kills Mother: Guiding Children Through Trauma and Grief. London: Routledge.

Hester, M. \& Radford, L. (1996) Domestic Violence and Child Contact Arrangements in England and Denmark. Bristol: Policy Press.

Home Office (1993) Criminal Statistics: England and Wales. London: HMSO.

- (1994) Criminal Statistics, England and Wales. London: Research and Statistics Directorate.

Jaffe, P. G., Wolfe, D. A. \& Wilson, S. K. (1990) Children of Battered Women. Newbury Park: Sage.

Jensen, P. S. \& Shaw, J. (1993) Children as victims of war: current knowledge and future research needs. Journal of the American Academy of Child and Adolescent Psychiatry, 32, 697-708.

Kendall, P. C. (1991) Child and Adolescent Therapy: CognitiveBehavioral Procedures. New York: Guilford Press.

Lee, D. \& Turner, S. (1997) Theoretical models of post-traumatic stress disorder: cognitive-behavioural models of PTSD. In Psychological Trauma: A Developmental Approach (eds D. Black, J. Harris-Hendriks, M. Newman, et al), pp. 64-77. London: Gaskell.

Marans, S. \& Cohen, D. J. (1993) Children and inner city violence: strategies for intervention. In Psychological Effects of War and Violence on Children (eds L. Leavitt \& N. Fox), pp. 281-301. Hove: Laurence Erlbaum.

Masten, A., Best, K. M. \& Garmezy, N. (1990) Resilience and development: contributions from the study of children who overcome adversity. Development and Psychopathology 2, 425-444.

McIvor, R. (1997) Theoretical models of post-traumatic stress disorder: physiological and biological mechanisms. In Psychological Trauma: A Developmental Approach (eds D. Black, J. Harris-Hendriks, M. Newman, et al), pp. 55-60. London: Gaskell.

Mitchell, J. T. (1983) When disaster strikes: critical incident stress debriefing. Journal of Emergency Medical Services, 8, 36-39.

Najaran, L. M. Goenjian, A. K., Pelcovitz, D.et al (1996) Relocation after a disaster: Post-traumatic stress disorder in Armenia after the earthquake. Journal of the American Academy of Child and Adolescent Psychiatry, 35, 374-383.

Newman, M. (1997) Psychopharmacology. In Psychological Trauma: A Developmental Approach (eds D. Black, J. Harris-Hendriks, M. Newman, et al), pp. 294-304. London: Gaskell.

Osofsky, J. D. (1995) The effects of exposure to violence on young children. American Psychologist, 50, 782-788.

Parry-Jones, W., Barton, J. \& van Beinum, M. (1995) Psychological Support Programmes and Mental Health Services for Vulnerable Children and Young People in FYR Macedonia.
Glasgow: University of Glasgow, Department of Child and Adolescent Psychiatry.

Perry, B. D., Pollard, R. A., Blakley, T. L., et al (1995) Childhood trauma, the neurobiology of adaptation and "use-dependent" development of the brain: how "states" become "traits". Infant Mental Health Journal, 16, 271291.

Pynoos, R. S. (1992) Grief and trauma in children and adolescents. Bereavement Care, 11, 2-10.

- \& Nader, K. (1988) Children who witness sexual assaults on their mothers. Journal of the American Academy of Child and Adolescent Psychiatry, 27, 567-572.

---, Steinberg, A. M. \& Aronson, L. (1997) Traumatic experiences: the early organization of memory in schoolage children and adolescents. In Trauma and Memory: Clinical and Legal Controversies (eds P. S. Applebaum \& L. A. Uyehara), pp. 272-289. New York: Oxford University Press.

Raphael, B. \& Meldrum, L. (1995) Does debriefing after psychological trauma work? British Medical Journal, 310, 1479-1480.

Ressler, E., Boothby, N. \& Steinbock, D. (1988) Unaccompanied Children: Care and Protection in Wars, Natural Disasters and Refugee Movements. New York: Oxford University Press.

Richman, N. (1993a) Children in situations of political violence. Journal of Child Psychology and Psychiatry and Allied Disciplines, 34, 1286-1302.

- (1993b) Communicating with Children: Helping Children in Distress. London: Save the Children.

Robinson, R. C. \& Mitchell, J. T. (1993) Evaluation of psychological debriefings. Journal of Traumatic Stress, 6, 367-332.

Scheeringa, M. S., Zeanah, C. H., Drell, M. J., et al (1995) Two approaches to the diagnosis of post-traumatic stress disorder in infancy and early childhood. Journal of the American Academy of Child and Adolescent Psychiatry, 34, 191-200.

Shapiro, F. (1995) Eye Movement Desensitisation and Reprocessing. New York: Guilford.

Siegel, D. (1997) Memory and trauma. In Psychological Trauma: A Developmental Approach (eds D. Black, J. Harris-Hendriks, M. Newman, et al), pp. 44-53. London: Gaskell.

Skuse, D. \& Bentovim, A. (1994) Physical and emotional maltreatment. In Child and Adolescent Psychiatry Modern Approaches (eds M. Rutter, E. Taylor \& L. Hersov) (3rd edn), pp. 209-229. Oxford: Blackwell Scientific.

Smith, M. \& Bentovim, A. (1994) Sexual abuse. In Child \& Adolescent Psychiatry - Modern Approaches (eds M. Rutter, E. Taylor, \& L. Hersov) (3rd edn), pp. 230-251. Oxford: Blackwell Scientific.

Straus, M. A., Gelles, R. J. \& Steinmetz, S. (1980) Behind Closed Doors: Violence in the American Family. Garden City, NY: Doubleday Anchor.

UNICEF (1995) Children of Rwanda. Kigali: UNICEF.

Van der Kolk, B. A. \& Fisler, R. E. (1995) Dissociation and the fragmentary nature of traumatic memories: overview and exploratory study. Journal of Traumatic Stress, 8, 505-525.

Van Velsen, C. (1997) Theoretical models of posttraumatic stress disorder: psychoanalytical models. In Psychological Trauma: A Developmental Approach (eds D. Black, J. Harris-Hendriks, M. Newman, et al), Pp. 6163. London: Gaskell.

Warner, B. S. \& Weist, M. D. (1996) Urban youth as witnesses to violence: beginning assessment and treatment efforts. Journal of Youth and Adolescence, 25, 361-377.

World Health Organization (1992) The ICD-10 Classification of Mental and Behavioural Disorders. Geneva: WHO.

Young, B. \& Black, D. (1997) Bereavement counselling. In Psychological Trauma: A Developmental Approach (eds D. Black, J. Harris-Hendriks, M. Newman, et al), pp. 250-263. London: Gaskell.

Yule, W. \& Gold, A. (1993) Wise Before the Event: Coping with Crises in Schools. London: Calouste Gulbenkian Foundation. 


\section{Multiple choice questions}

1. Implicit memory:

a is easily accessible to retrieval

b of trauma is more likely to lead to dissociative experiences

c can be distinguished from explicit memory by being state-dependent

$\mathrm{d}$ is more dominant in young children than declarative memory.

2. Witnessing violence as a child:

$a$ is likely to result in perpetrating violence when an adult

b is associated with a high incidence of PTSD

c can cause attachment disorder

$d$ is less likely to cause PTSD if the victim is not a family member.
3. Early intervention and assessment post-trauma:
a has been shown to prevent PTSD
b is desirable for children
c should look at where the child should live
d may make a child's symptoms worse.

\section{ADVANCE NOTICE}

The Royal College of Psychiatrists in association with Sections of Forensic Psychiatry and CPS at Sheffield University, Rampton Hospital Authority and Rotherham Priority Health NHS Trust

\section{CONFIDENTIALITY - “WHO TO TELL WHAT TO, WHEN, AND WHY"}

\section{Swallow Hotel, Sheffield: 15-16 October 1998}

This conference aims to address the concept of confidentiality both from a general and a specifically psychiatric perspective in the context of rapidly changing expectations, practice, guidelines and statute and case law.

Over the one and a half days there will be eleven presentations by invited speakers as well as ample opportunity for small group discussion and plenary sessions.

This meeting is especially timely as the GMC is in the process of reissuing its guidelines on Confidentiality: Providing and Protecting Information, and the Royal College of Psychiatrists' working party is about to circulate its own draft proposals on confidentiality. It will provide a forum to take stock of the present status of professional confidentiality, to share contemporary difficulties and to encourage discussion of the particular dilemmas which arise in our different sub-specialities and roles.

Speakers so far include:

- Dr Susan Bailey

- Mr Christopher Bollas (Psychoanalyst)

- Professor Christopher Cordess

- Professor Raanan Gillon (Ethics)

- Mr Allan Levy QC

- Professor Roy McClelland
- Dr Susan Benbow

- Dame Fiona Caldicott

- Professor Bill Fulford

- Mr Anthony Harbour (Solictor)

- Mr Neil Marshall (GMC)

- Dr Judith Trowell

Full programme and booking forms are available on request, after $1 \mathrm{July}$ 1998, from the Conference Unit, Royal College of Psychiatrists, 17 Belgrave Square, London SW1X 8PG. Tel:0171 2352351 ext. 142, Fax 01712596507, E-mail:ASummers@rcpsych.ac.uk 